DOI:

\title{
THE VERBAL CODE OF THE TV SERIES DISCOURSE: REVISITING THE FUNCTIONS OF PRECEDENT PHENOMENA IN THE EPISODE TITLES
}

\author{
Anna Konstantinova \\ Dr.Sc., Professor \\ Kuban State University of Technology \\ (Krasnodar, Russia) \\ e-mail: constanna@mail.ru
}

\begin{abstract}
The present paper explores the peculiarities of employing precedent phenomena in the episode titles of the American political thriller "Scandal". First, the main features of the chosen TV series discourse are characterized; its narrative structure is highlighted and the significance of the titles in it is stressed. Second, the precedent phenomena used as the episode titles are systematized; the groups of precedent situations, precedent names, precedent texts, and the large group of precedent utterances are distinguished. The latter is constituted by idioms, paremias, quotes, titles of popular movies, inner precedent phenomena ("metaprecedents"), etc. both in standard and modified forms. The functions performed by the episode titles containing precedent phenomena are described. Theyincludeidentification, summary, conveyance of meaning, arousal of curiosity, and phatic function. The significant role of the selected precedent phenomena in the exploration of the main themes is discussed. It is concluded that the linguacultural specificity of the titles allows for their being crucial elements of the narrative.
\end{abstract}

Key words: political drama "Scandal", precedent phenomenon, episode title, discourse, TV

\section{ВЕРБАЛЬНЫЙ КОД ДИСКУРСА ТЕЛЕСЕРИАЛА: К ВОПРОСУ О ФУНКЦИОНИРОВАНИИ ПРЕЦЕДЕНТНЫХ ФЕНОМЕНОВ В НАЗВАНИЯХ ЭПИЗОДОВ}

\author{
Анна Александровна Константинова \\ Доктор филологических наук, профессор \\ Кубанский государственный технологический университет \\ (Краснодар, Россия) \\ e-mail: constanna@mail.ru
}

\begin{abstract}
Аннотация.Статья посвященарассмотрению специфики использования прецедентных феноменов в названиях эпизодов американского политическоготриллера «Скандал». Во-первых, описываются основные черты дискурса изучаемого телесериала, характеризуется его нарративная структура, отмечается значимость в ней заголовков эпизодов.Во-вторых, систематизируются прецедентные феномены, применяемые в качестве заголовков; выделяются группы прецедентных ситуаций, прецедентных имен, прецедентных текстов и многочисленная группа прецедентных высказываний, представленная идиомами, паремиями, цитатами, названиями известных фильмов, внутренними прецедентными феноменами («метапрецедентами»)и др. как в неизмененном, так и модифицированном виде.Выделяются функции прецедентных феноменов в заголовках телесериала, среди которых идентификация, передача значения/смысла, резюме, возбуждение любопытства и фатическая функция.Освещается значимостьотобранных прецедентных феноменов в раскрытии тематического содержания дискурса анализируемой драмы.Делается вывод о том, что лингвокультурнаямаркированность заголовков способствует их роли как эффективных вспомогательных элементов сериального нарратива.
\end{abstract}

Ключевые слова: политическая драма «Скандал», прецедентный феномен, название эпизода,дискурс, телевидение

ВВЕДЕНИЕ. Несмотря на внедрение новейших технологий передачи визуальной информации, телевидение до сих пор остается одним из самым популярных и предпочитаемых развлечений в мире; при этом в нынешнем высоко медиатизированном (подверженном влиянию масс-медиа) обществе важная роль в определении того, что актуально, социально значимо и, следовательно, заслуживает внимания, все еще принадлежит телевидению. Так, современное ТВ предоставляет богатый материал для ученых, работающих в области когнитивнодискурсивныхисследований; анализу подвергаются разные виды кинематографического дискурса.В настоящейстатьематериалом для рассмотрения послужил образец довольно популярного жанра телесериала политический триллер «Скандал» («Scandal»), характеризующийся, по нашим наблюдениям, «многослойностью» вербального кода, которая достигается, помимо прочего, с помощью активного применения прецедентных феноменов разного порядка в качестве названий эпизодов.

МЕТОДИЧЕСКАЯ БАЗА ИССЛЕДОВАНИЯ. В ходе нашей работы применялись дискурсивный анализ;контекстуальный анализ; метод лингвистического описания, включающий в себя приемы наблюдения, интерпретации, сопоставления, обобщения и классификации; элементы метода статистической обработки и обобщения полученных данных. В связи с избранным объектом исследования мы опирались также на основные положения теории прецедентности и придерживались традиционного понимания прецедентных феноменов 
(далее - ПФ) как ядерного элемента когнитивной базы, к которым относят феномены 1) актуальные в когнитивном (познавательном и эмоциональном) плане;2) имеющиесверхличностный характер, т. к. хорошо известны представителям некоторой лингво-культурной группы;3) обращение к которым постоянно возобновляется в речи (дискурсе) представителей данного языкового сообщества (Krasnykh 2003: 170; Gudkov 2003).

РЕЗУЛЬТАТЫ И ДИСКУССИЯ. Характеристика дискурса политического триллера «Скандал» Политический триллер является субжанром политической драмы: как и полагается триллеру, телевизионный сериал «Скандал» нацелен на то, чтобы вызывать у зрительской аудитории чувство волнительного ожидания и создавать атмосферу подозрения (“suspense”); при этом он содержит политический компонент, т.к. действия происходят на фоне политических интриг и ожесточенной борьбы за власть. Выбор обозначенного телешоу обусловлен несколькими причинами: 1) стабильно высокие рейтинги сериала на протяжении всех семи сезонов (выходил в эфир с 2012 г. по 2018 г.) и, следовательно, его популярность и массовость аудитории;2) соответствие «профилю качественного телевидения» (Robert J. Thompson 1997: 13-16) в связи с сильным авторским началом; 3) неоспоримые, с нашей точки зрения, лингвистические достоинства.

Действие в теледраме «Скандал», полностью оправдывающей свое название, разворачивается вВашингтоне - центре политической жизни США. Главная героиня сериала - высокообразованная, сильная и успешная афроамериканка - антикризисный менеджер Оливия Поуп, в прошлом работавшая в Белом доме. Оливия руководит агентством O.P.A. (OliviaPope\&Associates), сотрудников которого, ставших близкими ей людей с непростыми судьбами, она гордо называет «гладиаторами в костюмах» (“gladiatorsinasuit”). В каждой серии герои, прибегая к мыслимым и немыслимым ресурсам (подобно римским гладиаторам, пользовавшимся различными орудиями для сражения), предпринимают попытку разрешить потенциально скандальную ситуацию и тем самым предотвратить кризисы разного уровня - личного, семейного и даже государственного. Клиентами «гладиаторов», таким образом, становятся высокопоставленные политики, влиятельные бизнесмены и публичные персоны. С другой стороны, в фокусе внимания в сериале оказываются и «обитатели» Белого дома, вовлекаемые в часто жестокие политические игры и интриги в их постоянной борьбе за власть. С главным представителем «политического Олимпа», сериальным президентом Фитцжеральдом Грантом, Оливию Поуп связывают любовные отношения.

Для более полной характеристики дискурса телесериала считаем важным остановиться на его нарративной структуре, которая, как известно,в качестве составных элементоввключает весь ряд эпизодов, между которыми выстраивается семиотическая цепь, чьи звенья связаны содержательными, жанровыми, стилистическими, формальными признаками (Kozlov 2003). Намеренно создаваемая фрагментированность дискурса телесериала порождает асимметрию в отношениях между текстом и аудиторией и, тем самым, стимулирует процесс порождения идей («ideation)», побуждает зрителя на основе извлечения из памяти информации (ретенция) из прошлой серии, выстраивать возможные траектории развития событий в следующей (Iser, 1989: 31 - 33). Во фразе «theaudienceislefttoknow», произнесенной продюсером и идейным вдохновителем драмы «Скандал» Ш. Раймс в одном из телевизионных интервью, заключается, пожалуй, ее писательская философия. Как создатель шоу она предпочитает, чтобы именно зритель, будучи снаряженным арсеналом средств для интерпретации, стал автором главных выводов и умозаключений.Отметим также тот факт, что в рассматриваемом телевизионном шоу отправитель сообщения явно не идентифицируется (к примеру, отсутствует субъект наррации, нет замечаний невидимого нарратора). В нем, наряду с визуальной нарративной инстанцией, используется набор культурогенныхфеноменов, среди которых прецедентные единицы, употребляемые в названиях эпизодов сериала. Как нам представляется, ПФ как элементы когнитивной базы могут служить эффективными вспомогательными компонентами нарратива: анонсировать тему/содержание эпизода, давать ключи к истолкованию происходящих событий и т. д. Кроме того, название эпизода - начальная «порция информации», которую получают актеры при первом совместном прочтении сценария (“tableread”). Так, этот структурный элемент нарративаявляется одним из опорных моментов для интерпретации актерами сюжета, действий воплощаемых ими персонажей ивыстраивания своей дальнейшейигры, которая, в свою очередь, становится интерпретационной подсказкой длязрительской аудитории.

Наши собственные наблюдения за функциями названий эпизодов политического триллера «Скандал», содержащих ПФ и, следовательно, маркированных в лингвокультурном плане, мы базировали на классификации функций названий литературных произведений, предложенной К. Тоденхагеном(Приводится по: Gill, 2008: 22 - 23). Несколько модифицировав ее в ходе анализа, мы пришли к выводу, что назначением названий серий вданном телесериале являются: 1) идентификация (заголовки поддерживают фрагментированность дискурса, выделяя эпизоды-звенья семиотической цепи); 2) резюме (служат средством краткого изложения сути/содержания серии и таким образом снижают информационную нагрузку, выделяя наиболее значимые информационные элементы); 3) передача значения/смысла (являются средством внутренней экспликации дискурса, интерпретационным ключом); 4) возбуждение любопытства (вовлечение зрителя в своего рода интеллектуальную игру) и, что специфично для анализируемого дискурса, 5) выполнение 
фатической функции (прецедентные феноменыкак символы культуры, элементы когнитивной базы выступают своеобразным маркером общественности («sociality»), а их знание и правильное толкование в связи с развитием сюжета являются залогом формирования чувства включенности и принадлежности к некоторой общности активной зрительской аудитории).

Систематизация прецедентных феноменов, используемых в названиях эпизодов телесериала «Скандал». Анализируемая политическая драма «Скандал» выходила в эфир на протяжении семи сезонов и насчитывает 124 эпизода. По нашим наблюдениям, в абсолютном большинстве случаев (104) в качестве названий серий авторами шоу избираются прецедентные феномены (всего в 20 случаях не был установлен статус прецедентности/прецедентного феномена). Традиционно выделяемые классы ПФ (Красных 2002: 50, 51) представлены и в названиях эпизодов драмы «Скандал»: 1) универсальные прецедентные феномены: библеизмы“TheLastSupper” (четвертый сезон восьмой эпизод, далее - S4E8), S4E18 “HonorThyFather” и др.; 2) национально-прецедентные феномены: S5E15 “PencilsDown” (слова, произносимые учителем/преподавателем университета и сигнализирующие обокончании времени, отведенного на выполнение тестовой работы), S2E14 "WhiskeyTangoFoxtrot" (эвфемистическая замена грубого выражения, часто представляемого аббревиатурой WTF, с использованием принципа военного фонетического алфавита), S4E2 "StateoftheUnion"(ежегодное Посланиео положении союза президента США Конгрессу) и многие другие культуроспецифические фразы; 3) социумно-прецедентные (рассмотрены ниже и в рамках данного исследования трактуются как «метапрецеденты» или внутренние прецеденты сериального дискурса).

В ходе анализа было также выявлено, что в качестве заголовков серий политической драмы «Скандал» применяются все типы ПФ, с большим перевесом в строну прецедентных высказываний. Так, можно выделить:

1) прецедентную ситуацию (четвертый сезон седьмой эпизод, далее - S4E7 “BabyMadeaMess”);

2) прецедентные имена (S3E6 “Icarus”, S5E8 “Rasputin” и др.);

3) прецедентные тексты, представленные через связанные с ними прецедентные имена/ высказывания (S7E4 "LostGirls"/“lostgirls" $\leftarrow$ "lostboys" $\leftarrow$ "PeterPan” Дж. Барри; S1E8 "НарpyBirthday, Mr. President” одноименная песня М. Монро, исполненная ею по случаю 45-летия президента Дж.Ф. Кеннеди; S5E1 "HeavyIstheHead" распространенная искаженная цитата из пьесы У. Шекспира «Генрих IV, часть 2» "Uneasyliestheheadthatwearsacrown” и др.);

4) прецедентные высказывания, представленныеединицами с различнымиисточниками происхождения:

a) кинодискурс (наиболее многочисленная подгруппа заголовков эпизодов): названия кинофильмов (политический триллер "EnemyoftheState" (S1E4), комедия “TheOtherWoman" (S2E2), криминальная драма “AnInnocentMan” (S4E6), документальный фильм о сексуальных скандалах в американской политике S4E2 “BeltwayUnbuckled” и мн. др.Модификации подвергается, к примеру, название выдающейся кинокартины "MrSmithGoestoWashington" (политическая комедийная драма 1939 г.). В эпизоде третьего сезона под названием "MrsSmithGoestoWashington" (S3E3) клиенткой ОРА становится женщина, которая пытается выяснить правду о своем сыне, обвиненном в терроризме, и для этого приезжает в Вашингтон и нанимает для расследования Оливию Поуп и ее команду;

б) музыкальный дискурс (названия популярных песен и музыкальных альбомов): S4E7 "PutaRingonIt" (название песни американской исполнительницы Бейонсе “SingleLadies (PutaRingonIt)”);S5E9 “BabyIt'sColdOutside" - названиеизвестнейшей композиции Ф. Лессера, использованной в фильме «Дочь Нептуна» и удостоенной награды «Оскар» в 1949 г. и др.;

в) названия радиопередач: S2E12 “TruthorConsequences” - название популярного американского шоу розыгрышей, изначально транслируемого по радио (1940-47 гг.), а затем по телевидению вплоть до 1988 г.;S2E21 “AnyQuestions?”- такое название носила радиопрограмма канала BBCRadio 4;

г) фразеологический фонд, представленный

идиомами: "Dirty Little Secrets" (= a partner a person doesn't want their friends to know about), S1E5"Crash and Burn" (= to fail completely);S7E2 "Pressing the Flesh" (= shake hands and mingle with people especially when running for office)идр.;

цитатами: S2E18 “Molly, YouinDangerGirl” - фраза из киноленты Дж. Цукера «Привидение», адресованная персонажем В. Голдберг, мошенницей Одой Мэй Браун, главной героине Молли; S3E4 "SayHellotoMyLittleFriend" - слова, произносимые гангстером Тони Монтана, сыгранным Аль Пачино в криминальной драме “Лицо со шрамом”, перед тем как он разрушает дверь выстрелом из своего автомата и др.; устойчивыми фразами: название эпизода S5E6 “GetOutofJail, Free” отсылает к ставшей метафорической фразе "getoutofjailfreecard”, обозначающей то, что поможет выйти из нежелательной ситуации и в буквальном смысле называющей элемент популярной настольной игры «Монополия»; название эпизода S5E18 “TillDeathDoUsPart”являетсяфразой из текста традиционной католической свадебной клятвы и др.; 
паремиями. В названиях эпизодов всего выявлено шесть единиц, среди которых одна пословица в стандартной форме - S5E13«TheFishRotsFromtheHead», четыре паремии подвергаются модификации - акроним «YOLO» (S3E9) (распространенный ныне способ «кодирования» современной пословицы “Youonlyliveonce”, часто используемой для обоснования совершения опрометчивого/глупого поступка); значимые для сюжета сериала лексические замены происходят в названиях серийS4E4 "LikeFather, LikeDaughter" (Cp."Like father, like son”)иS2E5 “All Roads Lead to Fitz” (Cp. All Roads Lead to Rome).В названии эпизода пятого сезона S5E7 “Even the Devil Deserves a Second Chance" (Cp. "Everyonedeservesasecondchance”) с помощью лексической субституции первого компонента происходит уточнение значения традиционной паремии. Еще в одном названии (S3E5) создается подобная паремии единица - псевдопословица - “MoreCattle, LessBull” (построена по традиционной структурно-семантической модели "MoreX, lessY"/Сp., к примеру, "Morehaste, lessspeed”, "Moreactions, lesswords” и, исходя из толкования событий в серии, можно утверждать, выражает суждение обобщающего характера - «чем больше людей привлекается к расследованию «классифицированного» дела (“morecattle”), тем больше вскрывается секретов и лжи (“bull”), связанных с ним);

собственно дискурс сериала «Скандал», из которого заимствуются ставшие для него знаковыми рекуррентные фразы, являющиеся ключевымисодержательными центрами нарратива и несущие мощную смысловую нагрузку. В этой связи мы предлагаем их трактовать как своего рода «метапрецеденты», или внутренние дискурсивные прецеденты (будут рассмотрены ниже).

Анализ роли прецедентных феноменов в раскрытии тематического содержания дискурса телесериала «Скандал». Интересными представляются также результаты рассмотрения роли выделенных ПФ в раскрытии тематического содержания дискурса телевизионной драмы «Скандал», которые, как показывает анализ, обозначают несколько ключевых тем, раскрываемых в обсуждаемом шоу. Целесообразным считаем в рамках данной статьи изложить наблюдения относительно функционирования внутренних прецедентных феноменов («метапрецедентов»), а затем остановиться на главной теме телесериала - теме политики.

Название пилотного эпизодателешоуS1E1 "SweetBaby" содержит рекуррентную фразу, которая маркирует одну из главных линий взаимоотношений главной героини Оливии Поуп - романтическуюс вязь с сериальным президентом США Фитцжеральдом Грантом. В данной серии фраза «вводит» самую первую интригу и скандально опасную ситуацию - интимную связь президента со стажером Белого дома Амандой Теннер, которая угрожая публичным освещением дела, становится клиенткой ОРА. В заголовок открывающего третий сезон эпизода S3E1 “It'sHandled” вынесена излюбленная фраза О. Поуп, которую она зачастую произносит еще до окончания дела (“considerit'shandled”) и которая отражает, пожалуй, основные черты личностного портрета Оливии как делового человека, в чьих руках оказываются судьбы людей, а иногда целых государств - амбициозность, самоуверенность, даже претензию на всемогущество. Тема «гладиаторства»/«гладиаторов» (“gladiating”) - концепта, заключающего в себе философию осуществления антикризисного управления в «большой политике» - поддерживается несколькими рекуррентными словосочетаниями, также фигурирующими в названиях следующих эпизодов: S2E1 “WhiteHat'sOff”, S2E22 “WhiteHat'sBackOn” и S4E12 “GladiatorsDon'tRun”. Так, названия открывающей и финальной серий второго сезона, отмеченного большим количеством флешбэков, раскрывающих нелицеприятную предысторию происходящих в настоящем событий и развивающихся конфликтов, содержат устойчивое выражение “whitehat”, обозначающее честного и благородного человека или символ добродетели и правосудия. Данный концепт, таким образом,представлен в сериале какнаивысшая ценность, являющаяся моральным ориентиром в действиях Оливии и компаньонов,от которого персонажи всё-таки иногда отклоняются. Так, в эпизоде “WhiteHat'sOff” им приходится препятствовать правосудию подделкой улик, чтобы скрыть более серьезные свои деяния - вмешательство в ход выборов президента Гранта, но при этом спасти от тюремного заключения невинную сотрудницу Квин Перкинс, которая оказалась втянутой ими в политические игры не по своей воле. В финальном эпизоде второго сезона “WhiteHat'sBackOn” Оливии и ее помощникам удается восстановить «моральное равновесие», когда в результате их расследования наибольшие злодеи несут наказание и Оливия Поуп получает белую шляпу в подарок от Генерального прокурора США. Ее она заслуживает еще и потому, что принимает решение остаться работать со своими товарищами-«гладиаторами», хотя получает возможность находиться рядом с президентом в качестве первой леди. В эпизоде “GladiatorsDon'tRun” компаньонам приходится в очередной раз объединиться, даже несмотря на внутренние серьезные разногласия, чтобы предпринять попытку освободить Оливию из плена после ее заказного похищения.

Важным считаем здесь также отметить, что, будучи глубоко противоречивым и сложным персонажем, совершившим множество злых и добрых дел, Оливия Поуп может рассматриваться как яркий пример анти героини. Однако, по замечанию Ш. Раймс, в финале сериала авторы попытались представить завершение долгого путешествия Оливии, ее возвращение из «тьмы к свету», а не вынести оценку политической жизни в Вашингтоне. Оставив для догадок то, как сложитсядальнейшаясудьбаглавных персонажей сериала, создатели, все же, предложили в качестве дискурсивных подсказок для интерпретации финаланазвания двух последних эпизодов, которые (что примечательно) содержат метапрецедентные высказывания, хорошо знакомые 
зрительской аудитории. В серии S7E17 “StandingintheSun” наконец разоблачаетсясверхсекретная организация специальных агентов и шпионов В613, которая действовала без ведома федерального правительства и любыми методами пыталась обеспечить защиту Республики. Так, фраза “standinthesun” (не раз адресуемая Оливии как альтернатива порочной жизни в большой политике) выносится в название предпоследней серии и дает зрителю понять, что в ней совершаются знаковые дела во имя справедливости. В финальной серии S7E18 “OvertheCliff” содержится своего рода девиз «гладиаторов», произносимый ими в решающих жизненных ситуациях и служащий символом их сплоченности, самоотверженности и взаимной преданности. В данном эпизоде, рискуя многим, они все же доводят главное дело уничтожения В613 до конца, совершая, таким образом, метафорический «прыжок с обрыва». Будучи использованными в названиях двух последних эпизодов, эти внутренние ПФ «намагничивают» дискурс своей прецедентной силой, передают важное когнитивное содержание.

Относительно заглавной темы исследуемой драмы - темы политики - заметим, что она представлена несколькими направлениями, среди которых тема «президентства» и/или получения одной изруководящих должностей в Белом доме как заветной цели крупных политиков (обозначаемых в дискурсе с помощью анималистической метафоры “bigdogs”) и исследование тех методов и путей, с помощью которых происходит реализация этой цели и возможных ее последствий. По замыслу Ш. Раймс, Овальный офис символбезграничной власти - изображается как место, оказывающее порочное влияние на приближающихся к нему людей. В этой связи одним из главных политических скандалов, за развитием которого следит телезритель, становитсяфальсификация результатов выборов президента Ф. Гранта, которая была осуществлена по заговору приближенных к нему людей - членов его команды (среди которых О. Поуп) и его супруги Мелли Грант - без его ведома, так какмолодой кандидат в президенты - порядочный и амбициозный человеком - не допустил бы нечестной победы.

Седьмой эпизод первого сезона носит лаконичное название S1E7 “Grant: ForthePeople”. В нем после получения угрозы об огласке супружеской неверности и его отношений со стажером Белого дома А. Тэннер президент Ф. Грант считает единственно верным решением уйти в отставку, что к тому же даст ему возможность жить жизнью обычного человека рядом с любимой женщиной. Оливия, однако, осознает, что Фитц, будучи народным избранником, «принадлежит» не ей, а народу. Отсюда - элемент распространенной максимы А. Линкольна, выражающей один из основных демократических принципов США, в названии эпизода (Cp. "government of the people, by the people, for the people").Таким образом, из названия становится понятным, что О. Поуп и ее команда в очередной раз исправляют потенциально скандальную ситуацию, чтобы президент остался на своем посту. В эпизоде второго сезона S2E5 “AllRoadsLeadtoFitz", в названии которого модифицируется популярная паремия" All roads lead to Rome"посредством замены топонима "Rome" на внутреннее прецедентное имя "Fitz”, проливается свет на обстоятельства заговора, который привел Фитцжеральда Гранта к победе на президентских выборах.

Проблема цены/последствий крупных политических побед и завоеваний исследуется авторами телевизионного шоу, к примеру,в эпизодах S3E18 “ThePriceofFreeandFairElections" и S6E3 "FatesWorseThanDeath". В названии первого отмечаемфразу, обозначающую мировые стандарты политических выборов (“free and faire lections”) и передающуюв свернутом виде содержание серии и его тему: убийство сына президента Гранта помогает вырвать победу у соперника на выборах и во второй раз стать президентом США, так как вся нация скорбит вместе с ним и поддерживает его кандидатуру. В названии второго эпизода употребляется эвфемистическое выражение “fatesworsethandeath", исторически служившее обозначением изнасилования, но используемое ныне, как правило, в ироничных контекстах. Это правило, однако, нарушается в дискурсе телесериала, так как в обозначенной серии, пожалуй, худший из политических злодеев, глава администрации президента Сайрус Бин, оказывается на грани ареста за совершенное по его заказу убийство, что лишит его возможности исполнить заветную мечту и заполучить Овальный офис - для него это действительно хуже смерти!

Одной из отличительных черт дискурса драмы «Скандал» является «моральная неоднозначность»: его авторы предпринимают попытку исследовать как «темную», так и «светлую» стороны политических фигур. В названии эпизода пятого сезона S5E7 "EventheDevilDeservesaSecondChance”, как отмечалось выше, происходит значимое уточнение смысла традиционной пословицы за счет замены лексемы “everyone” на лексему “thedevil”, причем последняя служит в качестве собирательного имени для многих сериальных политиков-хищников.В обсуждаемой серии все они получают второй шанс, избегая наказания за свои деяния и продолжая вести «грязные игры», в то время как в ходе расследуемого агентством ОРА дела разоблачению подвергается известный писатель, виновный в сексуальном насилии над молодыми женщинами-писательницами.

ЗАКЛЮЧЕНИЕ. Итак, исследование показало, что отличительной чертой дискурса американского политического триллера «Скандал» является активное использование богатого арсенала прецедентных феноменов. В заголовках эпизодов фигурируют все типы ПФ, причем самую многочисленную группу составляют прецедентные высказывания, представленные единицами, заимствованными из разных видов 
медиадискурса ифразеологического фонда английского языка. Особого внимания заслуживает ряд внутренних прецедентных феноменов («метапрецедентов») сериала «Скандал» - рекуррентных фраз, являющихся ключевыми содержательными центрами нарратива и несущих мощную смысловую нагрузку. В некоторых случаях ПФ претерпевают изменения, модифицируются, что вызвано необходимостью их адаптации к сюжету телесериала. В ходе анализа было отмечено, что названия серий выполняют следующие функции: идентификация, передача значения/смысла, резюме, возбуждение любопытства и фатическая функция. Рассмотрение роли выделенных ПФ на уровне содержания дискурса показало, что ониспособствуют раскрытиюнескольких ключевых темтелевизионного шоу «Скандал», в том числе главной темы политики. Можно, таким образом, заключить, что лингвокультурнаямаркированность названий эпизодов в связи с использованием в них культурогенных текстов делает их эффективным элементом нарратива, этой краткой «инструкции» по истолкованию создаваемого в телесериале «возможного мира».

\title{
LIST OF REFERENCES
}

Gudkov B. D. Teoriya i praktika mezhkul'turnoy kommunikacii. M.: ITDGK «Gnozis», 2003.

Kozlov E. V. Seriynost' v paraliterature: intratekstual'nye obrazovaniya i izdatel'skie serii [Elektronnyy resurs]// Massovaya kul'tura na rubezhe XX-XXI vekov: Chelovek i ego diskurs. M.: Azbukovnik, 2003. S. 201 - 211. URL: http://ec-dejavu.ru/s/Serial.html (data obrascheniya 25.02.2019).

Krasnyh V. V. «Svoy» sredi «chuzhih»: mif ili real'nost'? M.: ITDGK «Gnozis», 2003.

Gill,P. (2008). "The Name of the Game": Form and Function of Episode Titles in Grey's Anatomy. Grace under Pressure: Grey's Anatomy Uncovered/ edited by Cynthia Burkehead and Hillary Robson. Cambridge: Cambridge Scholars Publishing.

Iser, W. (1989). Prospecting: From Reader Response to Literary Anthropology. Baltimore: The Johns Hopkins University Press.

Robert,Thompson J. (1997).Television's Second Golden Age: From Hill Street Blues to ER, Syracuse University Press.

\section{For citation:}

Konstantinova, A. (2019) THE VERBAL CODE OF THE TV SERIES DISCOURSE: REVISITING THE FUNCTIONS OF PRECEDENT PHENOMENA IN THE EPISODE TITLES. International Scientific-Pedagogical Organization of Philologists “ WEST-EAST ” (ISPOP). Scientific Journal WEST-EAST. Vol 1/1 N1 (October, 2019). pp. 82-87. doi:

\section{Для цитирования:}

Константинова, А.А. (2019) ВЕРБАЛЬНЫЙ КОД ДИСКУРСА ТЕЛЕСЕРИАЛА: К ВОПРОСУ О ФУНКЦИОНИ-РОВАНИИ ПРЕЦЕДЕНТНЫХ ФЕНОМЕНОВ В НАЗВАНИЯХ ЭПИЗОДОВ // International Scientific-Pedagogical Organization of Philologists “WEST-EAST” (ISPOP) . Scientific Journal WEST-EAST. Vol 1/1 N1 (October, 2019). C. 82-87. doi:

Information about the author: Anna Konstantinova - Dr.Sc., Professor, Kuban State University of TechnologyKrasnodar, Russia e-mail: constanna@mail.ru

Сведения об авторе: Константинова Анна Александровна - доктор филологических наук, профессор кафедры иностранных языков Кубанского государственного технологического университета, Кубань, Россия.

e-mail: constanna@mail.ru

DOI:

\section{NEW IDEOLOGEM IN THE DISCOURSE OF AMERICAN MEDIA}

\author{
Svetlana Kushneruk \\ Doctor of Philology, Professor \\ South Ural State Humanitarian Pedagogical University \\ (Chelyabinsk, Russia) \\ e-mail: Svetlana_kush@mail.ru \\ Maria Kurochkina \\ Candidate of Philology, Associate Professor \\ South Ural State Humanitarian Pedagogical University \\ (Chelyabinsk, Russia) \\ e-mail:kma1974@yandex.ru
}

Abstract.The paperfocuses on discursive actualization of a new ideologemof modern history - «Russia -adversaryof the West»in the
texts of American media. The main objective of the authors is to establish cognitive, axiological, pragmatic and discursive features of
the new ideologem in the American media discourse. Cognitive-discursive analysis is chosen as the main method of 